\title{
Ética del cuidado bajo la perspectiva de una líder indígena
} ecuatoriana

[Cómo citar este artículo: Revelo, G. Ética del cuidado bajo la perspectiva de una líder indígena ecuatoriana. Práctica Familiar Rural. 2019 noviembre; 4(3).]

\section{Grace Revelo[a]}

a. Estudiante de Doctorado en Bioética, Universidad el Bosque, Bogotá, Colombia. Universidad Central del Ecuador, Quito, Pichincha, Ecuador. Orcid: https://orcid.org/0000-0002-6448-0440

DOI: https://doi.org/10.23936/pfr.v4i3.108

Recibido: 15/09/2019 Aprobado: 21/11/2019

\section{RESUMEN}

Las comunidades indígenas han buscado la libertad e igualdad en sus contextos sociales, las mujeres líderes indígenas son escasas, ellas sufren de discriminación y rechazo por su sexo, color, raza y origen étnico. Conocer la historia de una mujer líder indígena del Ecuador y su lucha por la consecución de derechos para su comunidad, permite reflexionar sobre las situaciones de injusticia que atraviesan y visibilizar el aporte de las mujeres en la construcción de sociedades más justas. Desde la bioética, se debe buscar un planteamiento de justicia hacia las sociedades multiculturales, valorando, respetando, educando y dignificando a las minorías indígenas para que puedan ejercer sus derechos libremente y participen en la sociedad sin sufrir injusticias.

Palabras clave: diversidad cultural, mujer indígena, justicia social, liderazgo, respeto, bioética

Care ethics from the perspective of an Ecuadorian indigenous leader

\section{ABSTRACT}

Indigenous communities have sought freedom and equality in their social contexts, women indigenous leaders are scarce, they suffer from discrimination and rejection because of their sex, color, race and ethnicity. Knowing the history of a woman indigenous leader of Ecuador and her struggle for the attainment of rights for her community, allows us to reflect on the situations of injustice that are going through and make visible the contribution of women in the construction of fairer societies. From bioethics, an approach to justice towards multicultural societies should be sought, valuing, respecting, educating and dignifying indigenous minorities so that they can freely exercise their rights and participate in society without suffering injustices. 
Keywords: cultural diversity, indigenous women, social justice, leadership, respect, bioethics

1. Introducción

Mi voz tiene otra semántica, tiene otra música. Hablo de la resistencia, de la indignación, de la justicia ira de los traicionados y de los engañados. De su derecho y de su deber de rebelarse contra las transgresiones éticas de que son víctimas cada vez más (1).

Este artículo de reflexión es resultado de la lectura "Tránsito Amaguaña su testimonio" que relata la vida de una líder indígena que luchó por la justicia social de los indígenas en el Ecuador. La perspectiva Bioética de su vida la asumo desde el punto de vista de la ética del cuidado que según Gilligan (1985) recupera la trascendencia de considerar la pluralidad, el contexto y la particularidad, se inquieta por la actividad de brindar cuidado, centra el desarrollo moral en torno al entendimiento de la responsabilidad y las relaciones y al entendimiento de derechos y reglas (2).

La importancia de la recuperación de historias de vida de las líderes indígenas y de empoderamiento de las mujeres sirve para comprender las trayectorias personales, los factores que contribuyeron a su desarrollo y el aporte en la lucha por sus derechos y construcción de sociedades justas. Rosa Elena Amaguaña Alba, fue una líder de los levantamientos indígenas de Cayambe, Ecuador, realizados a mediados del siglo XX, antes de la Reforma Agraria (3). El nombre de Tránsito se le dio cuando se inscribió al Partido Comunista.

La infancia de Tránsito Amaguaña se desarrolla en una hacienda en la cual su padre trabajaba en como huasipunguero ${ }_{-}^{1}$ y su madre como huasicama ${ }^{2}$. Desde pequeña observó cómo el dueño torturaba a su padre cuando incumplía alguna situación del

${ }^{1}$ En Ecuador se les llamaba así a los campesinos que se les asignaba un huasipungo. El huasipungo, es un término quichua que se refiere a una porción de tierra que los propietarios de las haciendas otorgaban a cambio de trabajo sin remuneración. El huasipungo era sólo para los hombres, de tal manera que si fallecía el campesino, la esposa perdía la tierra asignada.

PRÁCTICA FAMILIAR RURAL| Vol.4 | No.3 | Noviembre 2019 | www.practicafamiliarrural.org trabajo, mientras que su madre como líder de su comunidad buscaba el reconocimiento económico del trabajo campesino (3).

A los nueve años Tránsito va a la escuela, estuvo seis meses en ella, fue discriminada y excluida por ser indígena a pesar de su habilidad de aprender rápidamente. A los diez años fue llevada a la hacienda para trabajar lavando y sirviendo a los dueños. La falta de oportunidades educativas puede ser una barrera importante para ejercer el liderazgo, generalmente, las mujeres campesinas tienen un nivel de escolarización bajo y algunas son analfabetas. El conocimiento científico es necesario para comprender y solucionar los problemas sociales (3).

Tránsito debe casarse a los catorce años para evitar que sea violada por los patrones, su madre le consigue un esposo once años mayor. Ella fue golpeada desde el primer día del matrimonio. Queda embarazada en cuatro oportunidades y uno de sus hijos tenía la piel más clara, el esposo alude que ella le ha sido infiel, al día siguiente encontró su hijo muerto. Después de varios maltratos él se va. Los abusos y violaciones son comunes en las mujeres campesinas, en sus propias comunidades es aceptado el maltrato físico, psicológico, verbal; surgiendo un ciclo de violencia y discriminación que se reproduce socialmente y muchas veces se debilita la solidaridad entre mujeres, aceptando la violencia como normalidad (3).

Desde edad temprana Tránsito conoció los caminos en búsqueda de justicia, participó en la lucha de su comunidad. Viajaba caminando hasta Quito para reclamar justicia; durante los reclamos se acercó a los socialistas comunistas con quienes se reunió a escondidas para formar los sindicatos agrícolas. La joven líder se unió al Partido Comunista y se sumó a los planteamientos de justicia y solidaridad que promovían los camaradas. Eso le valió la condena por la Iglesia y el aislamiento de la comunidad que manipulados por los curas repetían cosas injustificadas. Las oportunidades de ejercer liderazgo no son equitativas para hombres y mujeres (3).

Los indígenas se organizaron en sindicatos, las mujeres indígenas como Tránsito y su madre, fueron reprimidas y tuvieron que abandonar la tierra para esconderse de los

${ }^{2}$ El término huasicama se refiere al indio que trabaja en actividades relacionadas con el cuidado de la hacienda, recolección de leña, pastar cabezas de ganado, ordeñar vacas, entre otras. En el caso de las mujeres huasicamas no recibían remuneración económica y debían dejar sus bebés a los pocos días para dedicarse a esta labor. 
militares que fueron llamados por los dueños de las haciendas para aplacar la rebelión. La casa de la madre de Tránsito fue destruida en varias oportunidades, en una ocasión, los hermanos de Tránsito destruyeron la casa obligados por los militares. Debieron vivir una vida clandestina durante quince años (3).

En agosto de 1944 se crea la Federación Ecuatoriana de Indios (FEI), Tránsito fue figura clave de este logro junto con Dolores Cacuango, otra líder indígena. En su plataforma política la FEI insistió en el traspaso de tierras a los trabajadores del campo, el paso a la reforma agraria y la protección de las mujeres indígenas. Después de quince años de luchas, consiguen con la FEI el aumento del salario, dejar de trabajar los sábados, suprimir las huasicamías y los servicios y suprimieron los diezmos y las primicias (3).

Tránsito fue encarcelada dos veces, la primera vez cuando se unió a Dolores Cacuango para pedir al Estado brindar educación a los niños y niñas indígenas. La segunda, después de un año de haber viajado a Cuba y Rusia, acusada de traer instrucciones para armar la revolución en Ecuador. El sometimiento, la discriminación y privación de la libertad por ser líder indígena, la hace víctima de violencia política. Ella superó la humillación, el rechazo y la marginación (3).

Después del segundo encarcelamiento, Tránsito continúa en la búsqueda de organización de los indígenas en las cooperativas. Las grandes extensiones de tierra fueron parceladas por el Estado y se repartieron por medio de las cooperativas, las tierras tenían un costo que pudo ser pagado por los campesinos, algunas mujeres también recibieron terrenos que tuvieron que devolver porque la falta de tiempo para asistir a la reunión de las cooperativas (3).

Después de años de lucha a favor de las comunidades indígenas, Tránsito no recibe tierra por medio de las cooperativas, sino que vivió en un lote que le fue otorgado por el gobierno. Fallece antes de cumplir los cien años.

Los pueblos indígenas viven en todas las regiones del mundo y ocupan aproximadamente el $22 \%$ del territorio del planeta. Cuentan con entre 370 y 500 millones de personas y representan la mayor parte de la diversidad cultural del mundo, ya que han creado y hablan la mayoría de las casi 7.000 lenguas del mundo. Muchos pueblos indígenas siguen enfrentando situaciones de marginación, de pobreza extrema y otras violaciones de derechos humanos (4).
La concepción de justicia social en el modelo de sociedad actual establece que una sociedad es justa si cuenta con mecanismos que garanticen las condiciones y la distribución de bienes y cargas de tal manera que satisfagan las necesidades básicas de sus miembros (5). La determinación de las necesidades básicas debe ser de manera autónoma, decidiendo cuáles son y la forma aceptable de satisfacerlas, de acuerdo a su cultura. Una sociedad justa debe proporcionar las condiciones para la preservación y florecimiento de los miembros de un determinado pueblo. El principio estaría basado en establecer mecanismos sociales de distribución de bienes, beneficios y cargos que amparen los pueblos indígenas y su acceso a los recursos naturales y las necesidades básicas. La cultura de la interculturalidad debe entenderse como la mayoría de sociedades son multiculturales, por lo tanto, todos los pueblos deben ser respetados y merecen tener las condiciones adecuadas para su bienestar y el ejercicio de su autonomía.

Las mujeres indígenas son objeto de discriminación múltiple e intersectorial por motivo de sexo, raza, color y origen étnico. Esta situación lleva al deterioro de su calidad de vida, quedando expuestas a la pobreza, violencia, discriminación y la limitación o negación de sus derechos. Sin embargo, las mujeres indígenas han comprobado una gran capacidad de resiliencia y son una importante fuerza social. Existen varios estudios que reconocen el aporte de los movimientos de mujeres indígenas en la lucha por la ampliación y reconocimiento de sus derechos, no sólo para combatir la desigualdad sino para defender el derecho a ser diferente (6).

La Justicia Social debe proveer elementos específicos para el contexto en que ellas se desarrollan para tratar de entender las prácticas sociales y particularidades de la cultura indígena. Además, debe eliminar las barreras para la participación de las mujeres líderes indígenas que permitan prácticas justas en sus pueblos y culturas (7, 8).

El análisis Bioético en este caso, propongo realizarlo desde la mirada de la ética del cuidado, debido a la existencia de una perspectiva diferente que define la moral en términos de relaciones interpersonales en lugar de hacerlo concentrándonos en reglas y principios abstractos, como lo propone Gilligan (2). Se debe enfatizar la importancia del vínculo afectivo, de comprender que las relaciones humanas son de dependencia, además son frágiles y discontinuas. Estas relaciones son fundamentales para adquirir competencias éticas y para convertirse en seres autónomos. En el caso de Tránsito, ella dependía en su infancia de sus padres, observó cómo fueron tratados en condiciones de inequidad, ambos trabajaban y sólo el padre recibía una remuneración. 
Tránsito tuvo acceso al estudio caracterizado por la ausencia de apoyo de sus profesores y compañeros al ingresar, durante su vida escolar recibió humillaciones y fue despreciada por ser indígena, los demás la consideraban ignorante. En su vida adulta, pese a su actitud de liderazgo, no obtuvo vivienda por sus méritos debido a su falta de recursos económicos, además, al ser mujer no podía aspirar al huasipungo asignado a los campesinos. Se le privó de libertad teniendo que casarse a temprana edad y soportó los maltratos de su esposo durante varios años, posteriormente, resistió la represión al andar clandestinamente durante quince años, y finalmente fue encarcelada debido a su capacidad de liderar su comunidad marginada.

La solución a los problemas sociales debe darse institucionalmente, en el caso de los indígenas, es necesario contextualizar cada cultura particular y brindar soluciones desde la misma comunidad, su bienestar debe provenir de ellos, no puede ser impuesta de fuentes externas. Para Tránsito la agrupación de campesinos era importante, de esta manera, buscaba en conjunto brindar solución a las situaciones de injusticia que vivían, la falta de salario, el trabajo sin días libres, etc.

La vida de esta líder indígena permite visualizar algunas de las problemáticas que viven los campesinos indígenas en sus comunidades, desligarnos de esta realidad sería incongruente cuando se quiere hablar de Bioética. Como orientadora, la Bioética debería retomar los testimonios de los indígenas campesinos en sus contextos para revisar si los Derechos Humanos se cumplen en sus comunidades, retomando los conceptos de justicia, solidaridad y dignidad humana. El sumak kawsay pretende reconstruir la vida y la ética que ordenaba la existencia de las comunidades indígenas antiguamente. Se debe buscar la promoción humana a la educación, la justicia, el bienestar social y el cuidado de la vida. Finalmente, la Bioética debería recomendar acciones políticas que eviten la opresión de las minorías, retomando los conceptos de dignidad, libertad y equidad.

A manera de conclusión, se debería afinar el sentido de la injusticia, haciendo hincapié en lo que está mal, determinando porqué lo está y qué se puede hacer para solucionar la situación. Se debe buscar una justicia social en la que se cuente con mecanismos que garanticen las condiciones y la distribución de bienes y cargas de tal manera que satisfagan las necesidades básicas de los miembros de la sociedad. La Bioética debe considerar las minorías indígenas buscando soluciones a los problemas sociales en cuanto a la justicia y el bienestar.
REFERENCIAS BIBLIOGRÁFICAS

1. Freire P. Pedagogía de la Autonomía: saberes necesarios para la práctica educativa [Internet]. Sao Paulo: Paz y tierra; 2004 [revisión 2019; consultado 2019 Sep 14]. Disponible en:

https://www.buenosaires.gob.ar/areas/salud/dircap/mat/matbiblio/freire .pdf

2. Casado D, Sanz M, Tizón J. Crianza saludable. Fundamentos y propuestas prácticas [Internet]. Madrid, Seminario de Intervención y Políticas Sociales; 2012 [Consultado 14 Sep 2019]. Disponible en:

http://www.unavarra.es/digitalAssets/158/158821 6 Casado Crianzasaludable.pdf

3. Rodas R, Transito Amaguaña Su testimonio. Quito: Comisión Nacional Permanente de Conmemoraciones Cívicas; 2007.

4. Organización de las Naciones Unidas para la Educación, la Ciencia y la Tecnología [Internet]. Los Pueblos Indígenas y la UNESCO; 2017 [Consultado 14 Sep 2019]. Disponible en:

http://www.unesco.org/new/es/indigenous-peoples/

5. Olive L. Multiculturalidad, justicia social y pueblos indígenas. Estado del desarrollo económico y social de los pueblos indígenas de Guerrero. SIPIG UNAM [Internet]. 2009. [Consultado 14 Sep 2019]. Disponible en: http://www.nacionmulticultural.unam.mx/edespig/diagnostico_y perspe ctivas/RECUADROS/CAPITULO\%201/4\%20Multiculturalidad.pdf

6. Weise C, Álvarez I. Identidad y percepciones de género. Retos para la formación de mujeres líderes indígenas. Revista Aposta [Internet]. 2018. [Consultado 14 Sep 2019]. Disponible en: http://www.apostadigital.com/revistav3/hemeroteca/cweise.pdf

7. Murillo J. Hacia un Concepto de Justicia Social. Revista Iberoamericana sobre Calidad, Eficacia y Cambio en Educación [Internet]. 2011. [Consultado 14 Sep 2019]. Disponible en: http://www.redalyc.org/pdf/551/55122156002.pdf

8. Murillo J, Román M, Hernández R. Evaluación Educativa para la Justicia Social. Revista Iberoamericana de Evaluación Educativa. 2011. [Consultado 14 Sep 2019]. Disponible en: https://revistas.uam.es/index.php/riee/article/view/4467/4893 